\title{
Acoustic sensors for rare porpoise
}

\section{SAN FELIPE, MEXICO}

After two months of laying down acoustic devices across the Gulf of California in Mexico, three vessels have completed a survey of the world's most endangered marine mammal.

The sophisticated array tracked the estimated 150 remaining porpoises, known as vaquitas (Phocoena sinus). The research, completed this week, could help authorities to prevent the last of the vaquita from becoming fishing by-catch. The team eventually hopes to establish a network of buoys around a broad reserve, to serve as a model for porpoise conservation around the world.

Mexican authorities have tried to protect the vaquita by buying up hundreds of fishing skiffs, but the fishermen always return. The vaquita is ranked 78th on the EDGE list of Evolutionarily Distinct and Globally Endangered mammals.

In 1997, a visual survey estimated the vaquita population at nearly 600 porpoises. Each vaquita can be up to 1.5 metres long and weighs about 50 kilograms (A. M. JaramilloLegorreta, L. Rojas-Bracho and T. Gerrodette Mar. Mamm. Sci. 15, 957-973; 1999). Over the past three years, scientists have used a cabin cruiser converted into an acoustic lab to follow the animals' sounds - and listened in as the number of vaquita sonar clicks dropped dramatically.

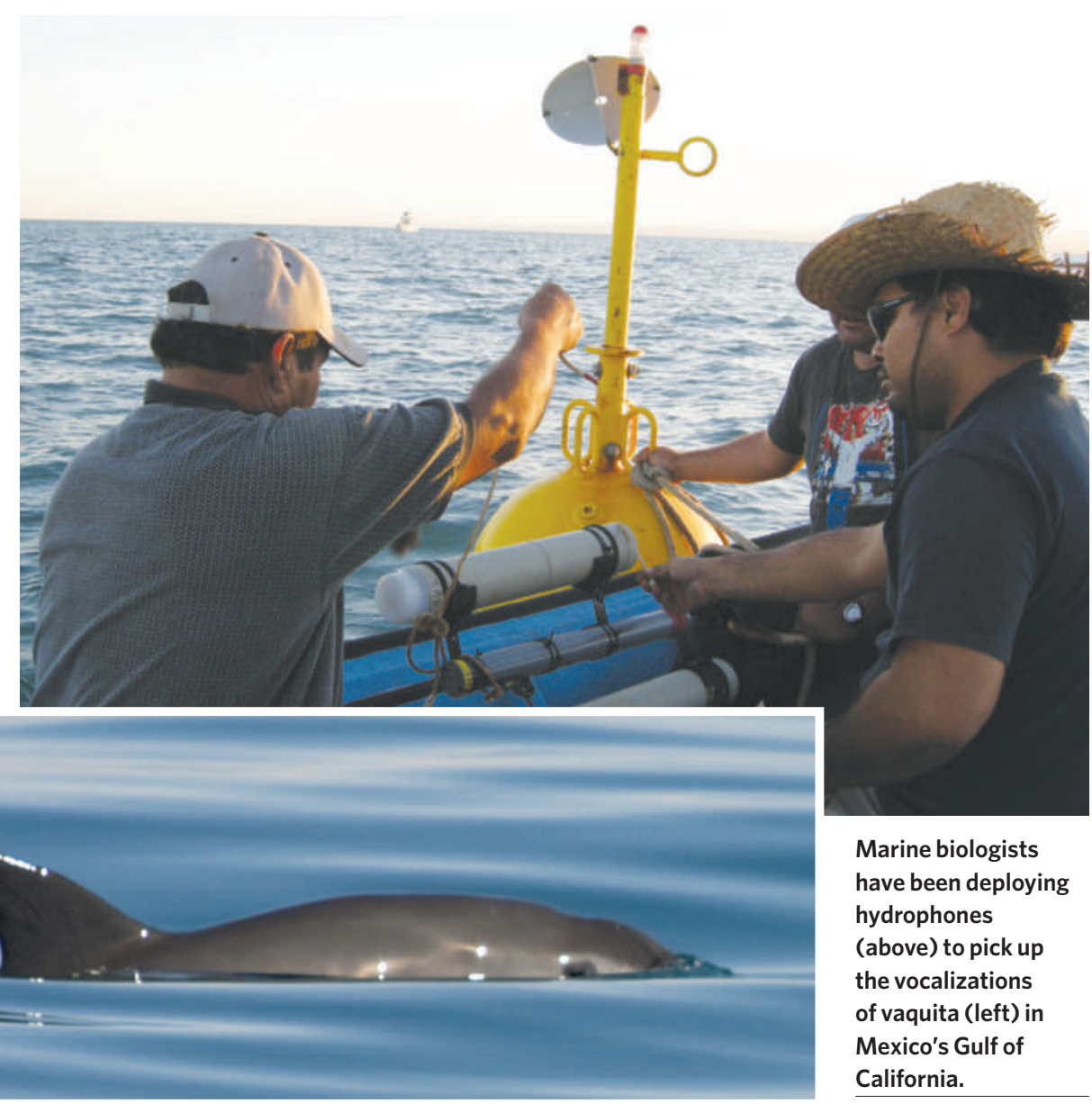

\section{Sound trackers}

These observations provided the impetus for the new survey. Small and understandably nervous of boats, vaquita are difficult to find, especially when the Gulf of California's high winds turn a bathtub surface into a choppy mass of white caps. On a clear day, the best equipment can capture a signal only if the animal is within a couple of hundred metres of the boat. "We have been lucky finding them," says co-chief scientist Lorenzo Rojas Bracho, who coordinates Mexico's Marine Mammal Research and Conservation project from the National Institute of Ecology's office in Ensenada. Even so, he and his co-workers often go for days without seeing any.

Their study is the most sophisticated to date and involved deploying four types of hydrophone. During the surveys, one hydrophone was towed behind the vessels along transect lines, and the others were deployed on buoys or hung overboard for 12-24 hours at a time at multiple locations in the shallow waters of the gulf.

The buoy hydrophones, powered by offthe-shelf batteries, were encased in plastic pipe weighted to the sea floor. Crew members aboard the Mexican cruiser, the Koi Poi, retrieved them about every two weeks. From there Rojas Bracho's colleagues, Armando Jaramillo Legorreta and Gustavo Cardenas Hinojosa, downloaded the acoustic records to an onboard computer "We have been lucky before resetting and resubmerging the hydrophones. They then sent the data to a nearby vessel, whence they were e-mailed to institutes in Japan, the United Kingdom or La Jolla, California.

If it works as well as its architects anticipate, the array could be the next step in expanding monitoring efforts in other regions. For instance, one of the buoy-deployed acoustic monitors was originally developed by team member Tomonari Akamatsu of the National Research Institute of Fisheries Engineering in
Ebidai, Japan, and first used to study fin-less porpoises in Asia. Those monitors have also been laid in the Yangtze River in China to try to find the baiji (Lipotes vexillifer), which was declared probably extinct in 2006. And earlier this month, Akamatsu put them in a reservoir behind a dam on the Ganges River in India, to count the endangered Ganges River dolphin (Platanista gangetica).

Even with the monitoring, the vaquita's numbers are so low that it may yet go the way of the baiji. Fishermen along the gulf's broad, white beaches insist that there are no vaquita left, in the hope that the government will not restrict their activities. When they are shown videos of the animals in the wild, they call it a computer trick.

First results from the new survey are expected to be presented at a conference in Mexico early in 2009. Then Mexican officials will use it to design a system to monitor, and perhaps prevent, the extinction of the vaquita.

Rex Dalton 